\title{
Respiratory syncytial virus glycoproteins uptake occurs through clathrin-mediated endocytosis in a human epithelial cell line Abel Gutiérrez-Ortega ${ }^{1}$, Carla Sánchez-Hernández² and Beatriz Gómez- García*3
}

\author{
Address: ${ }^{1}$ Centro de Investigación y Asistencia en Tecnología y Diseño del Estado de Jalisco A.C., Av. Normalistas \# 800, Colinas de la Normal, C.P. \\ 44270, Guadalajara, Jalisco, México, ${ }^{2}$ Centro Universitario de Ciencias Biológicas y Agropecuarias, Universidad de Guadalajara, Carretera \\ Guadalajara-Nogales km 15.5, Las Agujas, C.P. 45110, Zapopan, Jalisco, México and ${ }^{3}$ Departamento de Microbiología y Parasitología, Facultad de \\ Medicina, Universidad Nacional Autónoma de México, Circuito Interior, Ciudad Universitaria, DF México, México \\ Email: Abel Gutiérrez-Ortega - agutierrster@gmail.com; Carla Sánchez-Hernández - sanchez.cv@gmail.com; Beatriz Gómez- \\ García* - begomez@servidor.unam.mx \\ * Corresponding author
}

Published: 25 October 2008

Virology Journal 2008, 5:127 doi:10.1186/1743-422X-5-127

This article is available from: http://www.virologyj.com/content/5/I/I27

(C) 2008 Gutiérrez-Ortega et al; licensee BioMed Central Ltd.

This is an Open Access article distributed under the terms of the Creative Commons Attribution License (http://creativecommons.org/licenses/by/2.0), which permits unrestricted use, distribution, and reproduction in any medium, provided the original work is properly cited.
Received: 24 September 2008

Accepted: 25 October 2008

\begin{abstract}
Cell-surface viral proteins most frequently enter the cell through clathrin or caveolae endocytosis. Respiratory syncytial virus antigen internalization by immune cells is via caveolin, however, uptake of paramyxovirus cell membrane proteins by non-immune cells is done through clathrin-coated pits. In this work, the uptake of respiratory syncytial virus cell surface glycoproteins by non-immune human epithelial cells was investigated through indirect immunofluorescence with polyclonal antiRSV antibody and confocal lasser-scanner microscopy. Clathrin and caveolae internalization pathways were monitored through specific inhibitors monodansylcadaverine (MDC) and methylbeta-cyclodextrin (MBCD), respectively. Internalization of RSV antigens was inhibited by MDC but not by $M B C D$, implying that clathrin-mediated endocytosis is the major uptake route of RSV antigens by an epithelial human cell line.
\end{abstract}

\section{Findings}

Respiratory syncytial virus (RSV) is an enveloped, nonsegmented negative-stranded RNA virus, classified within the Paramyxoviridae family (genus Pneumovirus). Worldwide, it is implicated in the majority of lower respiratory tract infections in young children and it is a significant pathogen in the elderly and immunocompromised, being airway epithelial cells the main target for viral replication [1]. Its genome encodes two non-structural and nine structural proteins, three of which are transmembrane surface glycoproteins, F, G and SH. The disulfide-bonded protein $F$ (fusion protein) and the large $G$ protein (attachment protein) are the mayor antigenic determinants of the virus and play a crucial role in virus uptake/penetra- tion by the host, while SH inhibits tumor necrosis factoralpha (TNF-a) signalling [2-5].

Internalization of envelope viral components may be an important posttranslational regulatory mechanism that modulates the surface expression of viral glycoproteins. Spontaneous and anti-viral antibody-mediated endocytosis of cell surface envelope glycoproteins of paramyxovirus in non-immune epithelial cells is clathrin mediated [6]; in contrast, spontaneous endocytosis of RSV antigen in immune dendritic cells is via caveolin [7]. Previously, we reported that RSV antibody-dependent antigen internalization in non-immune epithelial cells is partially inhibited by incubation in hypertonic medium, suggest- 
ing the participation of a clathrin-mediated mechanism [8]. With the aim to confirm whether internalization of RSV cell surface antigen-antibody complexes in epithelial cells occurs through clathrin, the present study was undertaken. The uptake of the antigen-antiviral antibody complexes was blocked with specific clathrin and caveolae inhibitors and endocytosis was monitored.

The endocytosis analysis was performed by confocal lasser-scanner microscopy. For this purpose, HEp-2 cells were RSV infected for $12 \mathrm{~h}$. Origin of cells, virus propagation and infection procedures were previously reported [8]. The infected cells were washed and incubated with medium containing monodansylcadaverine (MDC) or methyl-beta-cyclodextrin (MBCD) at a concentration of 0.2 or $10 \mathrm{mM}$, respectively, for $30 \mathrm{~min}$ at $37^{\circ} \mathrm{C}$. Then the cells were washed and incubated in the presence of the inhibitors at the above concentrations with goat polyclonal anti-RSV antibodies (AB 1128; Chemicon) diluted 1:50 in Hanks Balanced Salt Solution (HBSS) for $30 \mathrm{~min}$ at $4^{\circ} \mathrm{C}$. After the cells were twice washed with ice-cold HBSS, they were immediately incubated at $37^{\circ} \mathrm{C}$ in prewarmed medium for 0,30 and 60 min to allow endocytosis to occur. Then, the cells were fixed and permeabilized with ice-cold methanol-acetone (1:1) for $5 \mathrm{~min}$, blocked with $2.5 \%$ bovine serum albumin (Sigma) in phosphate buffered saline (PBS). Internalized primary antibodies were detected with rabbit anti-goat fluorescein-conjugated secondary antibody (81-1620; Zymed) diluted 1:50 in PBS with $1 \%$ serum albumin. After extensive washing with PBS, the cells were mounted in Vectashield Propidium Iodide medium (Vector) to visualize counterstained nuclei. As control, infected cells without inhibitors were treated as described. The results are shown in figure 1.

As illustrated in Figure 1, in the absence of endocytosis inhibitors (DMSO treatment), RSV membrane proteins are initially located on the surface of infected cells $(0$ min), but, as time advances, they are found distributed inside the cells (30 and $60 \mathrm{~min}$ ). A noteworthy observation is that there was no noticeable difference between 30 and 60 min incubation times. The same happened in RSVinfected cells treated with the caveolae-uptake inhibitor MBCD. On the contrary, when infected cells were treated with the clathrin endocytosis inhibitor, MDC, RSV proteins located to the surface at all incubation times, which indicates that endocytosis of RSV membrane proteins depends on the clathrin-mediated pathway. Clathrinmediated endocytosis occurs faster in comparison to caveolae-mediated or bulk uptake, which is a consequence of membrane turnover. This explains why RSV proteins did not require more than 30 minutes to be taken up.

Figure 1 also shows that some proportion of RSV protein is still present at the surface of cells, even at the longest incubation time. This observation could indicate that not all RSV envelope glycoproteins are endocytosed. As measured by trypan blue staining, cell viability was unaffected by MDC or MBCD at the concentrations used here (data not shown), suggesting that endocytosis inhibition in MDC-treated cells is not a consequence of pleiotropic effects caused by MDC.

The role of clathrin-mediated uptake in any RSV-related mechanism was not clear until recently. Knockdown of genes associated with clathrin-mediated endocytosis as well as the expression of dominant-negative mutants that inhibit this uptake pathway blocks RSV infection, demonstrating an important role of clathrin for RSV entry [9]. Proteins that are internalized through the clathrin-mediated pathway usually bear the well characterized sorting signal, YXX $\Phi$, where $\mathrm{X}$ is any amino acid and $\Phi$ represents any hydrophobic amino acid. This sorting signal was identified in RSV SH glycoprotein as YFTL at its amino terminus located on the cytoplasmic side of the membrane $[10]$, however, there is no current evidence that proves this protein undergoes endocytosis.

In the present work, we confirm that clathrin-mediated endocytosis of RSV envelope proteins bound to antiviral antibodies takes place, but it remains to determine which of the proteins suffers endocytosis. Moreover, we do not know if this phenomenon is linked to an immune evasion mechanism. To this respect, there is a report that correlates internalization of plasma membrane-bound viral glycoproteins proteins to interference with an immune process known as antibody-dependent complementmediated cell lysis in pseudorabies virus-infected monocytes [11]. The possible biological importance of our finding requires further investigation.

\section{Competing interests}

The authors declare that they have no competing interests.

\section{Authors' contributions}

AGO participated in experimental design, carried out the endocytosis assay and drafted the manuscript. CSH carried out concentration, purification and titration of virus. BGG conceived of the study and helped to draft the manuscript. All authors read and approved the final manuscript. 


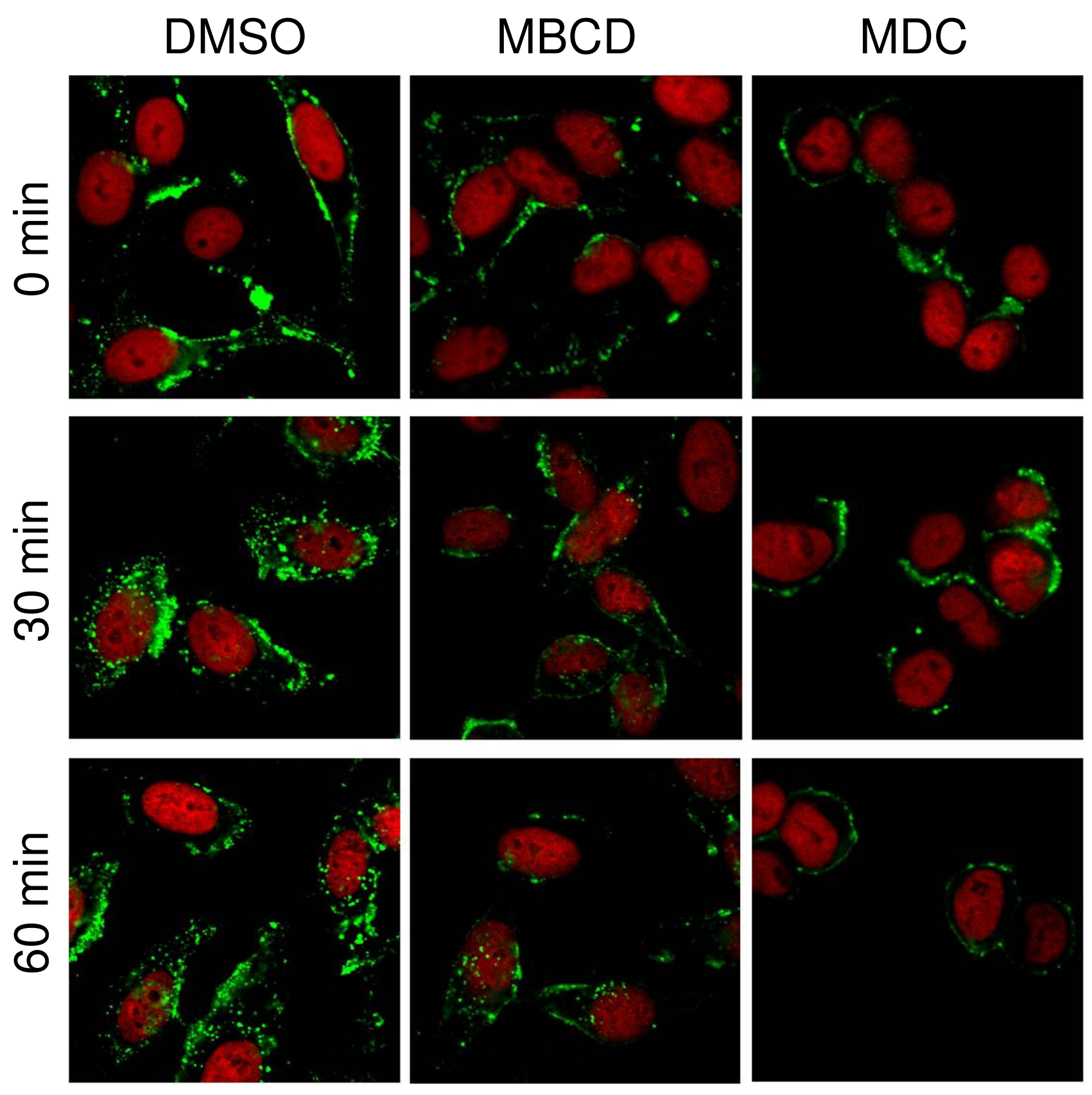

Figure I

Endocytosis of RSV envelope proteins in Hep-2 cells. Hep-2 cells were infected with RSV at a multiplicity of infection of 2. After $12 \mathrm{~h}$, the cells were incubated with anti-RSV goat antibody at $4^{\circ} \mathrm{C}$, rinsed and subsequently incubated at $37^{\circ} \mathrm{C}$ at different times $(0,30$ and $60 \mathrm{~min})$ to allow endocytosis to occur. The assay was performed in the presence of diluting agent dimethyl sulfoxide (DMSO), methyl-beta-cyclodextrin (MBCD) or monodansylcadaverine (MDC). The cells were fixed/permeabilized with ice-cold methanol:acetone and incubated with anti-goat IgG-FITC antibody. Later, unbound antibody was washed away and the cells were finally mounted in VectaShield Propidium lodide medium and analysed on an Olympus FVI000 confocal microscope. RSV antigens and nuclei appear in green and red, respectively. 


\section{Acknowledgements}

We thank Microscopy Laboratory of Instituto de Fisiología Celular, UNAM, for the kind assistance in confocal microscopy.

\section{References}

I. Collins PL, Chanock RM, Murphy BR: Respiratory syncytial virus. In Fields Virology 4th edition. Edited by: Knipe D, Howley P. Philadelphia: Lippincott Williams \& Wilkins; 200I: 1443-I 485.

2. Karron RA, Buonaugurio DA, Georgiu AF, Whitehead SS, Adamus JE, Clements-Mann ML, Harris DO, Randolph VB, Udem SA, Murphy BR, Sidhu MS: Respiratory syncytial virus (RSV) SH and G proteins are not essential for viral replication in vitro: clinical evaluation and molecular characterization of a cold-passaged, attenuated RSV subgroup B mutant. Proc Natl Acad Sci USA 1997, 94: | 396|-|3966.

3. Techaarpornkul S, Barreto N, Peeples ME: Functional analysis of recombinant respiratory syncytial virus deletion mutants lacking the small hydrophobic and/or attachment glycoprotein gene. J Virol 200I, 75:6825-6834.

4. Teng MN, Collins PL: Identification of the respiratory syncytial virus proteins required for formation and passage of helperdependent infectious particles. J Virol 1998, 72(7):5707-5716.

5. Fuentes S, Tran KC, Luthra P, Teng MN, He B: Function of the respiratory syncytial virus small hydrophobic protein. J Virol 2007, $81: 8361-8366$.

6. Vogt C, Eickmann M, Diederich S, Moll M, Maisner A: Endocytosis of the Nipah virus glycoproteins. J Virol 2005, 79:3865-3872.

7. Werling D, Hope JC, Chaplin P, Collins RA, Taylor G, Howard CJ: Involvement of caveolae in the uptake of respiratory syncytial virus antigen by dendritic cells. J Leukoc Biol 1999, 66:50-58.

8. Sarmiento RE, Tirado RG, Valverde LE, Gómez-García B: Kinetics of antibody-induced modulation of respiratory syncytial virus antigens in a human epithelial cell line. Virol J 2007, 4:68.

9. Kolokoltsov AA, Deniger D, Fleming EH, Roberts NJ Jr, Karpilow JM, Davey RA: Small interfering RNA profiling reveals key role of clathrin-mediated endocytosis and early endosome formation for infection by respiratory syncytial virus. J Virol 2007, 8I:7786-7800.

10. Rixon HWM, Brown G, Murray JT, Sugrue RJ: The respiratory syncytial virus small hydrophobic protein is phosphorylated via a mitogen-activated protein kinase $\mathrm{p38}$-dependent tyrosine kinase activity during virus infection. J Gen Virol 2005, 86:375-384.

II. Walle GR Van de, Favoreel HW, Nauwynck HJ, Pensaert MB: Antibody-induced internalization of viral glycoproteins and gE-gl Fc receptor activity protects pseudorabies virus-infected monocytes from efficient complement-mediated lysis. J Gen Virol 2003, 84:939-948.

Publish with Bio Med Central and every scientist can read your work free of charge

"BioMed Central will be the most significant development for disseminating the results of biomedical research in our lifetime. "

Sir Paul Nurse, Cancer Research UK

Your research papers will be:

- available free of charge to the entire biomedical community

- peer reviewed and published immediately upon acceptance

- cited in PubMed and archived on PubMed Central

- yours - you keep the copyright
BioMedcentral 